\title{
1 Segregation of floricolous ants along latitudinal and urbanization
}

\section{2 gradients}

3 Alan Vergnes ${ }^{\mathrm{a}-\mathrm{c}}$, Quentin Rome ${ }^{\mathrm{b}, \mathrm{d}}$, Inès Gayral ${ }^{\mathrm{a}, \mathrm{b}}$, Colin Fontaine $^{\mathrm{a}}$

4 a UMR 7204-CESCO. Centre d'Ecologie et des Sciences de la Conservation - Muséum national

5 d'Histoire naturelle

6 b Institut de Systématique, Évolution, Biodiversité - ISYEB - UMR 7205 - CNRS, MNHN,

7 UPMC, EPHE - Muséum national d'Histoire naturelle, Sorbonne Universités 57 rue Cuvier,

8 CP50 - F-75005, Paris, France

9 c Univ Paul Valery Montpellier 3, Univ Montpellier, CNRS, EPHE, IRD, UMR 5175 CEFE,

10 F34000, Montpellier, France

11 d UMS Patrimoine Naturel (PATRINAT), AFB, MNHN, CNRS, CP50, 45 rue Buffon 75005

12 Paris, France.

14 Corresponding author: Alan Vergnes

15 Orcid id : 0000-0002-6128-0793

16 alan.vergnes@univ-montp3.fr 
18

\section{Abstract}

Recent call has been made to study the biogeography of species interactions in order to better understand ecosystems' states and processes, as well as their response to global anthropogenic disturbances. Ants (Formicidae) are a dominant group of arthropods with a central role in ecosystem functioning. Many ant species, those feeding on liquids, are floricolous and consume nectar. The biogeography of ant-flower interactions is still poorly studied and especially in temperate area. Here we quantify variations in ant-flower interaction frequency in response to latitudinal and urbanization gradients at a country scale.

We used data from a flower-visitor monitoring program that includes pictures on 2511 flower plants across Continental France (Mainland) and over 4 years. We analysed the occurrence of the ant-flower interactions along two gradients: latitude and urbanization, this for 10 ant taxa corresponding to different taxonomical level (from family to species).

Ants visited $26 \%$ of the sampled plants. Most of the observed ant-flower interaction involved the subfamily Formicinae $(82.1 \%)$, followed by Myrmicinae and Dolichoderinae $(6.9 \%$ and $4.6 \%$ respectively). Globally, (i) the probability of occurrence was negatively related to latitudes (ii) and to urbanization at lower latitude. (iii) Responses to latitude among sub families, genus and species level responses were segregated and taxonomically aggregated.

At lower taxonomic levels we found clear latitudinal niche partitioning among ant taxa suggesting that competition, on both evolutionary and ecological time scales, is a major process structuring ant communities. Finally, our results highlight that the effects of large scale perturbation like urbanization can vary and affect latitudinal gradient.

Keywords: Insect distribution; Urbanization; Formicidae; Functional biogeography; Citizen

Science; Inter-specific interaction; Niche partitioning 


\section{Introduction}

A major aim of biogeography is to unravel the spatio-temporal distribution of species and ecosystems as well as the underlying abiotic factors and biotic processes shaping such distribution (Lomolino et al. 2006). This scientific field provided major insights for the understanding of natural gradients such as the decrease of diversity with increasing latitude at global scale (Gaston 2000, Rolland et al. 2014). There is growing evidence that global change can act as an additional driver shaping such large-scale diversity patterns. Indeed, human activities induce major environmental modifications such as climate or land use changes, with consequences on both species distribution and the functioning of species assemblages (Sala $e t$ al. 2000, Tylianakis et al. 2008). Understanding how such natural and human induce drivers of species distribution interact appears as one of the current challenges of biogeography (Parmesan et al. 2005).

Here we propose to address this challenge investigating the combined effects of latitude and urbanization on the distribution of the interaction between liquid-feeding ants and flower plants across Continental France.

Urbanization represents the prime driver of land use change in Europe (EEA 2010), with city areas increasing at a high rate and projected to double by 2030, reaching $6 \%$ of emerged earth's surface (Banque_Mondiale 2009). Urbanization has consequences far beyond cities' boundaries and impacts biodiversity patterns at a large scale (Pickett et al. 2011) mainly causing an impoverishment of communities and increasing the dominance of few urbanophile species (McKinney 2006).

For ants, most studies showed a negative effect of urbanization on species richness (Antonov 2008, Antonova and Penev 2006, Forys and Allen 2005, Holway and Suarez 2006, Lessard and Buddle 2005, López-Moreno et al. 2003, Majer and Brown 1986, Sanford et al. 2009, Thompson and McLachlan 2007, Uno et al. 2010, Xu et al. 1998) and one study a positive effect (Ives et al. 2011). The effects of urbanization on ant's abundance have been less studied 
and showed a more contrasted pattern (Antonova and Penev 2006, Buczkowski and Richmond 2012, Sanford et al. 2009, Uno et al. 2010). Indeed, rare species seem to exploit the modifications induced by urbanization and can reached high densities in cities (McKinney 2008, Vepsäläinen et al. 2008). To our knowledge, only one study has investigated the response of ant-plant interaction (Thompson and McLachlan 2007) which highlighted an increase of seeds' removal rate by the few species that remained in more urbanized forest.

Ants (Hymenoptera, Formicidae) are among the most abundant and ecologically significant groups on earth, sometime referred then as "the little things that rule the world" (Hölldobler and Wilson 1990), as they can deeply modify the environment, to the point of being considered as ecological engineers (Jones et al. 1994). As suggested by the correlated pattern of diversification between ants and angiosperm (Moreau et al. 2006), the interactions establish by ants with flowering plants might have been key to their current widespread distribution (RicoGray and Oliveira 2007). Their distribution varies along latitudinal gradient (Baroni Urbani and Collingwood 1977) and so their taxonomic diversity at both global (Dunn et al. 2009, Jenkins et al. 2011) and local scales (Del Toro 2013, Segev 2010).

Ant-plant interactions are diverse and distributed along an antagonism-mutualism continuum, with some ants feeding directly or indirectly on plants, inhabiting plants, protecting plant against herbivory, dispersing seeds, and even pollinating plants (Rico-Gray and Oliveira 2007). For species referred as liquid-feeding, which are frequent flowers visitors, consumer-resource interactions seem dominant. They often directly feed on plants, either from extrafloral nectary (Rico-Gray and Oliveira 2007) or within flowers (Herrera et al. 1984). Another explanation for the presence of ants on flowers is the mutualistic association between some ants and aphids. Indeed, many liquid-feeding ants plants have developed trophobiotic relationships with homopterous (aphids, coccids, membracids or lycaenids) and collect honeydew, such as the workers of the subfamilies Formicinae and Dolichoderinae and a few species in the genus 
Myrmica and Tetramorium of Myrmicinae (Stadler and Dixon 2005). While protecting aphids from potential parasitoids and predators they often patrol on flowers.

Using a large dataset coming from a citizen science program monitoring flower visitors across Continental France, we proposed to analyze the combine effect of latitude and urbanization on the presence of ants on flowers. According to spatial scale and taxonomic hierarchy, latitudinal gradients of biodiversity can show various patterns (Gaston 1996, Willig et al. 2003) : from positive to negative linear relationships, but also quadratic or non significant ones. In France, for example, Lobo et al. (2002) showed a quadratic relationship of dung beetles occurrences. We test whether ants' response to latitude is linear or quadratic and to what extent such latitudinal response is affected by urbanization. We carry out our analysis at various taxonomic levels, from family to species, looking for similarities and singularities in these responses.

\section{Material and Methods}

\section{Studied area}

The study took place across Mainland Continental France (here after France), spanning a latitudinal gradient from $51.08^{\circ}$ to $42.32^{\circ} \mathrm{N}$ (Fig. 1). It covers an area of $675,000 \mathrm{~km}^{2}$.

\section{The dataset}

Data comes from a citizen science program aiming at monitoring flower visitor across France using a standardized protocol fully described elsewhere (Deguines et al. 2012). Briefly, volunteers choose a flowering plant anywhere in France and take pictures of every insect visiting its flowers within a 20 -minute period. Then, insects and plant pictures are identified using online computer-aided identification tools (Causse et al. 2013) that propose sets of predefined taxa or morphospecies, including one "ant" taxa. The date, time, temperature and precise location of the observations are provided by volunteers when uploading their data on the program website (www.spipoll.org). Each set of identified plant and insects visiting it at a 
118 given time and place is referred as a collection. For the purpose of the present study, we used

119 all the collections recorded from 2010 to 2014 that comprised a total of 14,027 collections

120 including 2518 picture of ants (Fig 1. A). They spanned a latitudinal gradient from $42.36^{\circ}$ to

$12151.06^{\circ} \mathrm{N}$ and covering more than $99 \%$ of France latitudinal gradient. All ant pictures were then

122 identified to the highest taxonomic resolution possible by professional experts. S1 Table in

123 Supporting Information detailed these taxonomic groups, ranging from the family to the species

124 level.

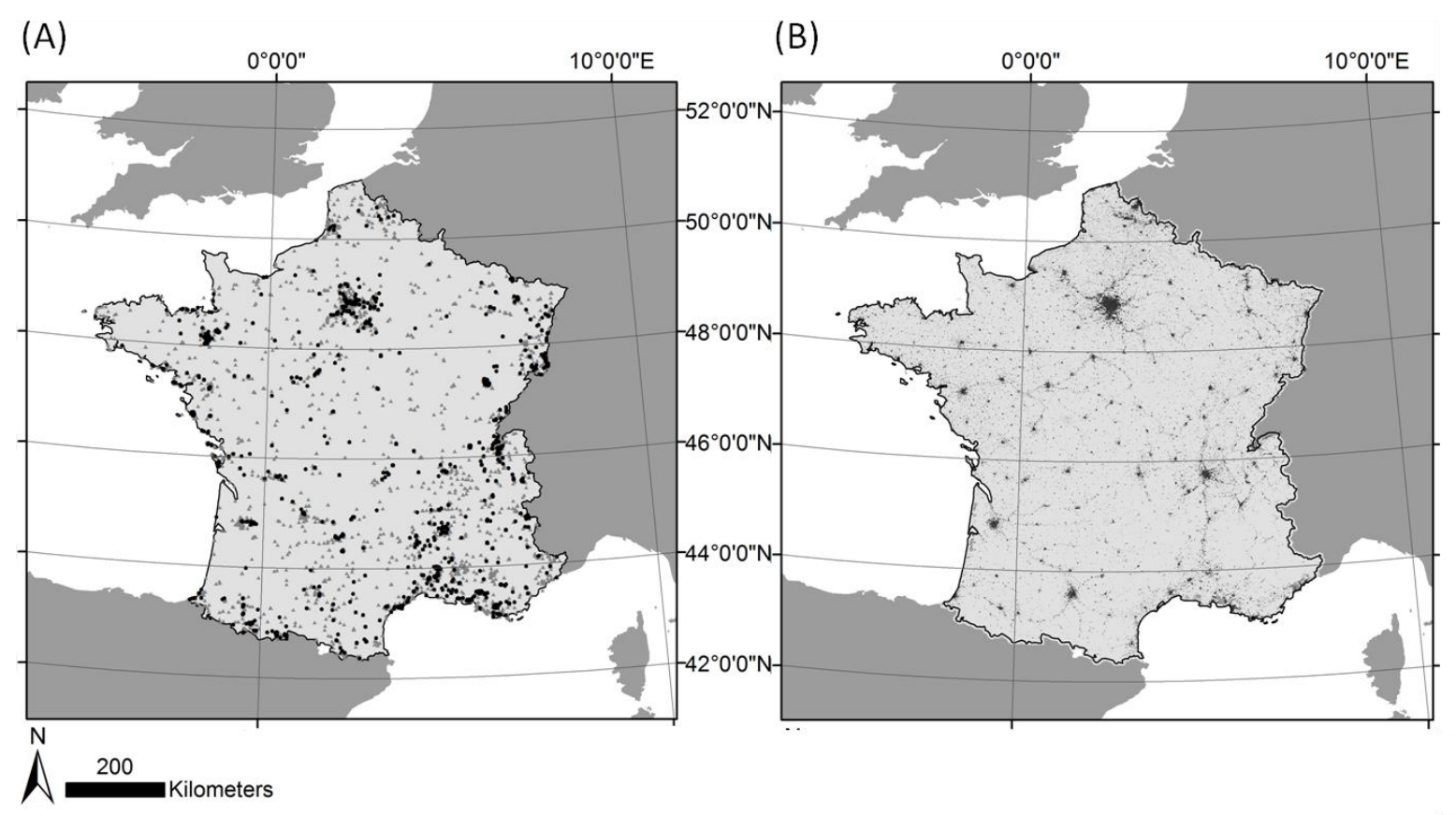

126 Fig 1. Locations of collections and urbanization in Continental France. In both maps,

127 Continental France is represented in light grey and the other emerged areas are represented in dark grey. (A) Collections with ant are represented by black dots and without by grey triangles.

(B) Urbanized areas are represented in black and other land uses in light grey.

\section{Urbanization index}

131 Urbanization was characterized by the artificial area category of the first level of Corinne Land

132 Cover 2006 database (raster version $25 \mathrm{~m}$ resolution, EEA 2010). In France, urbanization is 
133 positively correlated with latitude (EEA 2006). To disentangle the potential urbanization and

134 latitude effects, we followed the methodology proposed by Deguines et al. (Deguines et al.

135 2012) and calculated a relative urbanization index. Precisely, for each collection, we first

136 measured the proportion of urban land use within a $1 \mathrm{~km}$ radius. Then, for each collection we

137 subtracted to this proportion the mean proportion of urban land use within a $1 \mathrm{~km}$ radius of all

138 the collection located within a $100 \mathrm{~km}$ radius of the focal collection. This index of relative

139 urbanization is thus positive when the focal collection is more urbanized than the collections

140 that have been sampled regionally (i.e. within a $100 \mathrm{~km}$ radius) and negative when the focal

141 collection is less urbanized than the collection sampled regionally. Seven Collections that

142 presented less than 30 other collections in the $1 \mathrm{~km}$ radius where excluded from the analysis.

\section{4. Statistical Analysis}

144 We analysed the presence/absence of the nine most abundant ant taxonomic groups within the

145 collections using generalised linear models with binomial error distribution. We included as

146 explanatory variables in the model the latitude of the collection, its index of relative

147 urbanization and the interaction between both. To allow for quadratic response to latitude, we

148 also included the squared latitude and its interaction with the index of relative urbanization. All

149 models were simplified to the minimum adequate models based on the Akaike Information

150 Criterion (Johnson and Omland 2004). Significant of parameters was obtained with an Anova

151 type 3 test.

\section{Results}

\section{Identity of floricolous ants}

154 Flower visiting ants were present in $17.9 \%$ of the 14,027 collections included in our dataset,

155 totalising 2511 ant observations. We specified the identification of $92 \%$ of these observations

156 to a level ranging from subfamily to species (Table 1 and S1). 
Table 1. Occurrences of the 10 taxa studied.

Taxa levels

\begin{tabular}{|c|c|c|c|}
\hline family & subfamily & Genus & Species \\
\hline \multirow{6}{*}{$\begin{array}{c}\text { Ants } \\
\text { (Formicidae, } \\
\text { 2511) }\end{array}$} & Dolichoderinae (116) & & \\
\hline & \multirow{4}{*}{ Formicinae (2061) } & \multirow{2}{*}{ Camponotus (464) } & $\begin{array}{c}\text { Camponotus lateralis (Olivier, 1792) } \\
\text { (76) }\end{array}$ \\
\hline & & & $\begin{array}{c}\text { Camponotus piceus (Leach, 1825) } \\
\text { (120) }\end{array}$ \\
\hline & & Lasius (781) & $\begin{array}{c}\text { Lasius emarginatus (Olivier, 1792) } \\
\text { (116) }\end{array}$ \\
\hline & & Serviformica (697) & \\
\hline & Myrmicinae (174) & & \\
\hline
\end{tabular}

Authority are given for species level

159 This revealed that floricolous ants were not evenly distributed among subfamilies: $81 \%$

160 belonged to Formicinae, $7 \%$ to Myrmicinae and $5 \%$ to Dolichoderinae (Fig 2 (A)). The

161 remaining $8 \%$ of ant picture were not good enough to attribute them to a subfamily. Within

162 Formicinae, three genera were highly dominant: Lasius, Serviformica (subgenus of Formica)

163 and Camponotus that represented respectively $31 \%, 27 \%$ and $18 \%$ of all ant observations (Fig

1642 (A)). Within these genera, we were further able to identify three species: Lasius emarginatus,

165 Camponotus piceus and Camponotus lateralis that represented respectively $4.6 \%, 4.7 \%$ and

$1663.0 \%$ of all identified ants.

\section{Responses to latitudinal and urbanization gradients}

168 When analysing the distribution of ant observations across France, we found a significant

169 quadratic effect of the latitude indicating a hump-shaped response of ant presence with an

170 optimum around $45-46^{\circ} \mathrm{N}$ (Fig 2 (B) and Table 2). We further found a significant interaction

171 between the latitude and the index of relative urbanization indicating that urbanization affected

172 ant presence differently along the latitudinal gradient, with a negative effect at lower latitude

173 (Fig 2 (B) and Table 2). 


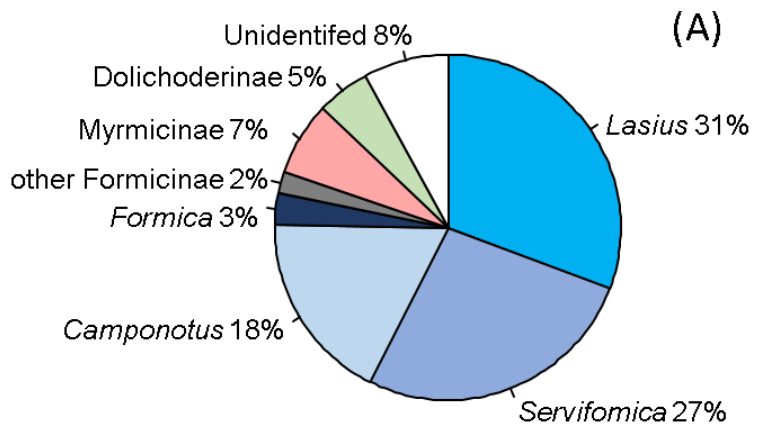

Dolichoderinae (C)

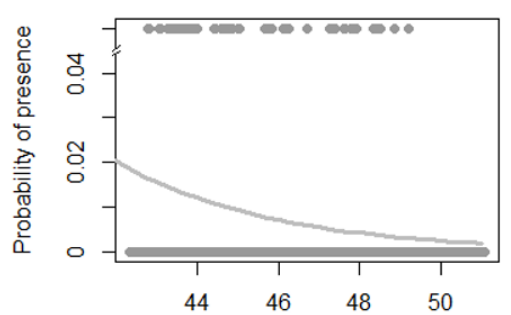

Camponotus sp

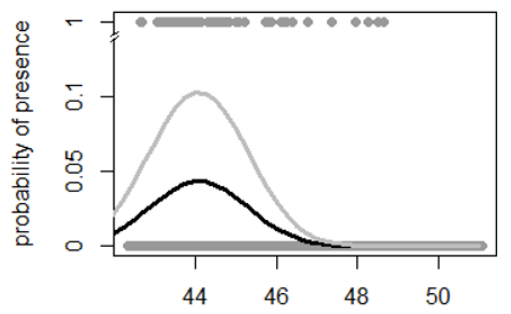

Camponotus lateralis (I)

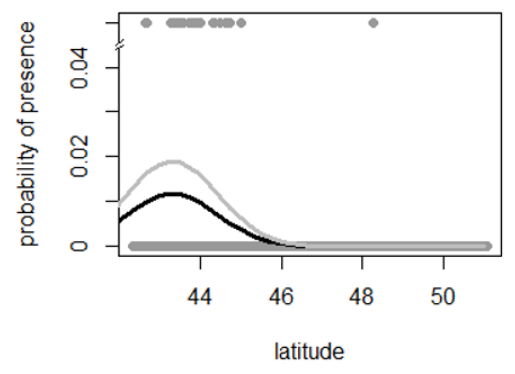

Myrmicinae

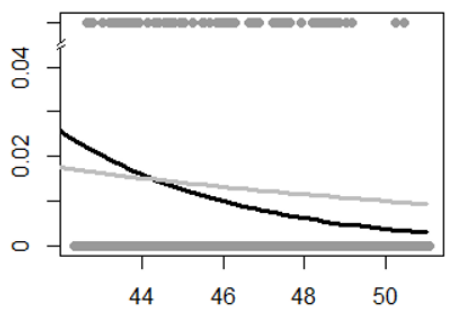

Serviformica sp (G)

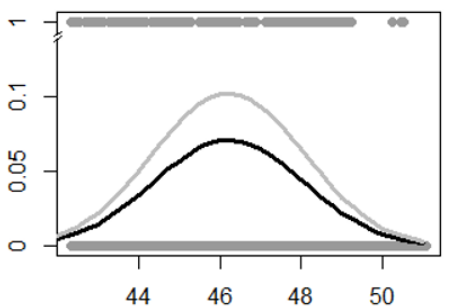

Camponotus piceus

(J)

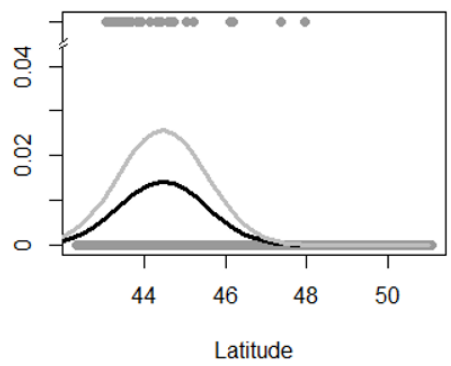

(D)
Ant

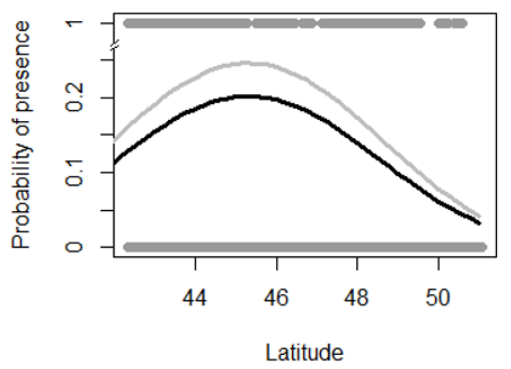

Formicinae

(E)

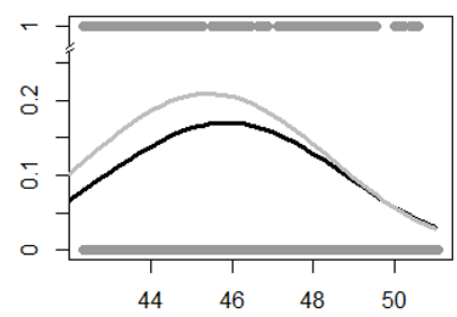

Lasius sp

(H)

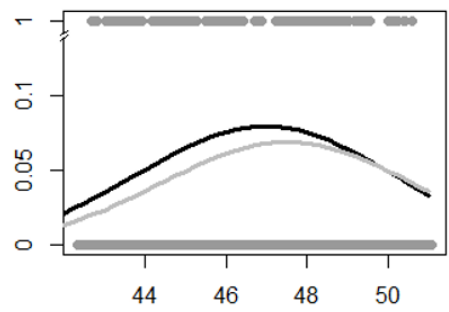

Lasius emarginatus (K)

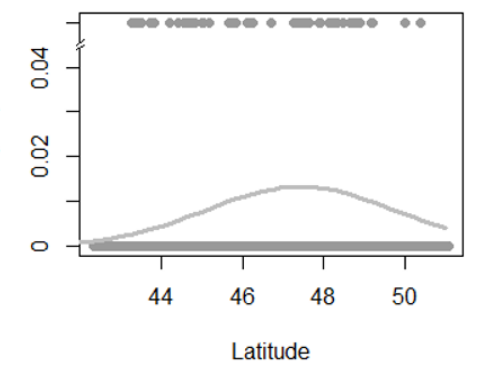

177 generalized linear models similar to the ones presented in the methods except that the relative

178 urbanization effect was treated as a factor with two levels: low (grey) and high (black), each

179 corresponding to half of the collections with respectively the lowest and highest values of

180 relative urbanization. 
182 The analysis of the presence of the three ant subfamilies highlighted striking differences among

183 them. First, Formicinae subfamily exhibited a pattern similar to the one observed for all the 184 ants, with a significant quadratic effect of the latitude with an optimum around $45-46^{\circ} \mathrm{N}$, and

185 a significant interaction between the latitude and the index of relative urbanization showing a 186 negative impact at low latitude (Fig 2 (E) and Table 2). Second, Myrmicinae subfamily 187 exhibited a significant interaction between the latitude and the index of relative urbanization 188 highlighting a positive impact at low latitude and a negative impact at high latitude (Fig 2 (D) 189 and Table 2). Finally, for Dolichoderinae subfamily, we found a significant effect of the latitude 190 (Table 2) revealing a steady decrease in the presence of this subfamily with increasing latitude $191 \quad$ (Fig $2(\mathrm{C}))$.

192 Scaling down our analysis at the genus level, we found a significant quadratic effect of latitude 193 for the three main genera belonging to Formicinae subfamily (Table 1). Interestingly, the 194 optimum was different for each genus. While Camponotus appeared to be the most southern genus with a presence peak around $44^{\circ} \mathrm{N}$, the optimum for Serviformica was around $46^{\circ} \mathrm{N}$ and Lasius appeared to be the northernmost genus with its optimum located between 46 and $48{ }^{\circ} \mathrm{N}$

197 (Fig 2 F, 2 G and 2 H, respectively). The presence of these three genera was also significantly 198 affected by the level of relative urbanization, but slightly differently. For Serviformica and 199 Camponotus genus, we found a significant negative effect of the relative urbanization (Fig 2 200 (F) and $2(\mathrm{G})$ and Table 2). For Lasius, we found a significant interaction between the relative 201 urbanization and the latitude indicating that the effect of urbanization was dependent on the 202 latitude, with a positive effect for intermediate latitudes (between $45-47^{\circ} \mathrm{N}$ ) (Fig 2 (H) and 203 Table 2). 
208 Table 2. Minimum adequate models for each of the nine ant groups.

\begin{tabular}{lrrrrrrr} 
& \multicolumn{4}{c}{ Ant (Formicidae) } & \multicolumn{3}{c}{ Formicinae } \\
Terms & Df & Estimate (Std) & Chisq & P value & Estimate (Std) & Chisq & P value \\
\hline Latitude & 1 & $5.59(0.59)$ & 95.94 & $<1.0 \mathrm{E}-4$ & $6.51(0.65)$ & 110.02 & $<1.0 \mathrm{E}-4$ \\
Urbanization $^{\text {Latitude }}{ }^{2}$ & 1 & $-0.01(0.001)$ & 36.71 & $<1.0 \mathrm{E}-4$ & $-0.06(0.02)$ & 8.7 & 0.003 \\
Latitude $x$ & 1 & $-0.06(0.01)$ & 99.79 & $<1.0 \mathrm{E}-4$ & $-0.07(0.01)$ & 112.86 & $<1.0 \mathrm{E}-4$ \\
Urbanization & 1 & & & & $0.001(4.4 \mathrm{E}-04)$ & 7.46 & 0.006
\end{tabular}

Myrmicinae

Dolichoderinae

\begin{tabular}{lrrrrrrr} 
Terms & Df & Estimate (Std) & Chisq & P value & Estimate (Std) & Chisq & value \\
\hline Latitude & 1 & $-0.15(0.04)$ & 16.68 & $<1.0 \mathrm{E}-4$ & $-0.26(0.05)$ & 30.58 & $<1.0 \mathrm{E}-4$ \\
Urbanization $^{\text {Latitude }}{ }^{2}$ & 1 & $0.15(0.06)$ & 6.33 & 0.012 & & & \\
Latitude x $^{\text {Urbanization }}$ & 1 & & & & & & \\
(1) & 1 & $-0.003(0.001)$ & 6.72 & 0.01 & & &
\end{tabular}

Serviformica

Camponotus

\begin{tabular}{|c|c|c|c|c|c|c|c|}
\hline Terms & Df & Estimate (Std) & Chisq & $P$ value & Estimate (Std) & Chisq & $P$ value \\
\hline Latitude & 1 & $14.57(1.23)$ & 171.97 & $<1.0 \mathrm{E}-4$ & $32.43(4.08)$ & 122.02 & $<1.0 \mathrm{E}-4$ \\
\hline Urbanization & 1 & $-0.01(0.003)$ & 25.58 & $<1.0 \mathrm{E}-4$ & $-0.02(0.002)$ & 68.47 & $<1.0 \mathrm{E}-4$ \\
\hline Latitude $^{2}$ & 1 & $-0.16(0.01)$ & 172.26 & $<1.0 \mathrm{E}-4$ & $-0.37(0.05)$ & 128.25 & $<1.0 \mathrm{E}-4$ \\
\hline $\begin{array}{l}\text { Latitude } \mathrm{x} \\
\text { Urbanization }\end{array}$ & 1 & & & & & & \\
\hline
\end{tabular}

\begin{tabular}{|c|c|c|c|c|c|c|c|c|}
\hline \multirow[b]{2}{*}{ Terms } & & & \multicolumn{3}{|c|}{ Lasius } & \multicolumn{3}{|c|}{ Lasius emarginatus } \\
\hline & & Df & Estimate (Std) & Chisq & $P$ value & Estimate (Std) & Chisq & $P$ value \\
\hline Latitude & & 1 & $5.31(0.94)$ & 34.09 & $<1.0 \mathrm{E}-4$ & $8.87(2.6)$ & 13.575 & $<1.0 \mathrm{E}-4$ \\
\hline Urbanization & & 1 & $0.06(0.03)$ & 4.41 & 0.036 & & & \\
\hline Latitude $^{2}$ & & 1 & $-0.06(0.01)$ & 32.95 & $<1.0 \mathrm{E}-4$ & $-0.09(0.03)$ & 13.068 & $<1.0 \mathrm{E}-4$ \\
\hline $\begin{array}{l}\text { Latitude } \\
\text { Urbanization }\end{array}$ & $\mathrm{x}$ & 1 & $-0.002(4.6 \mathrm{E}-4)$ & 3.85 & 0.05 & & & \\
\hline
\end{tabular}

\section{Camponotus lateralis}

Camponotus piceus

\begin{tabular}{|c|c|c|c|c|c|c|c|c|}
\hline Terms & & Df & Estimate (Std) & Chisq & $P$ value & Estimate (Std) & Chisq & $P$ value \\
\hline Latitude & & 1 & $35.17(15.45)$ & 10.21 & 0.002 & $38.75(7.82)$ & 50.881 & $<1.0 \mathrm{E}-4$ \\
\hline Urbanization & & 1 & $-0.01(0.01)$ & 4.3 & 0.038 & $-0.01(0.005)$ & 8.561 & 0.003 \\
\hline Latitude $^{2}$ & & 1 & $-0.41(0.18)$ & 10.21 & 0.001 & $-0.44(0.09)$ & 52.702 & $<1.0 \mathrm{E}-4$ \\
\hline $\begin{array}{l}\text { Latitude } \\
\text { Urbanization }\end{array}$ & $\mathrm{x}$ & 1 & & & & & & \\
\hline
\end{tabular}

For each group, the selected model was composed of the terms with Estimates, Chi-square

210 values and $p$-values.

212 Scaling further down our analysis to the three species we could identify and with sufficient data

213 (S1 appendix), we found a significant quadratic effect of latitude for each one. As for the three

214 genera analysed above, we found that the optimum varied among species: Camponotus lateralis

215 appeared to have the southernmost distribution, peaking around $43.5^{\circ} \mathrm{N}$ (Fig 2 (I)), followed 
by Camponotus piceus that peaked between 44 and $44.5^{\circ} \mathrm{N}$ (Fig 2 (J)). Lasius emarginatus had

217 the most northern and spread out distribution that peaked around $47.5^{\circ} \mathrm{N}(\operatorname{Fig} 2(\mathrm{~K}))$. While the 218 level of relative urbanization did not affect Lasius emarginatus (Fig 2 (K)), we found a significant negative effect of the relative urbanization for Camponotus lateralis (Fig $2(\mathrm{~F})$ and Table 2) and Camponotus piceus (Fig 2 (J) and Table 2).

\section{Discussion}

\section{Dominance of Formicinae on flowers}

At the subfamily level, almost $80 \%$ of the observed floricolous ants belonged to Formicinae subfamily. This result is consistent with Rico-Gray and Oliveira (Rico-Gray and Oliveira 2007) by the liquid-feeding (flower nectar or honeydew from aphids) behaviour of most species. Surprisingly, ants from the subfamily Dolichoderinae, which is also considered as highly floricolous (Rico-Gray and Oliveira 2007) were observed in $5 \%$ of the collections only. This overall low occurrence could be explained by the mainly southern distribution observed; this pattern is consistent with what is known of the distribution of this subfamily (Blatrix et al. 2013). Turning to Myrmicinae, their low occurrence in our dataset is consistent with their more predators and less floricolous habits than the two previous subfamilies (Rico-Gray and Oliveira

234 2007). Finally, the negligible occurrences of the last three subfamilies present in France, the 235 Ponerinae, (less than $0.1 \%$ ), none of the Leptanillinae nor the Proceratiinae is again consistent 236 with their almost strict edaphic behaviour in Continental France (Bernard 1968, Blatrix et al. 237 2013).

\section{Match and mismatch with known species latitudinal distribution}

239 Most of the knowledge about ant distribution is at the species level. Two of the three ant species 240 with sufficient data to analyse their latitudinal distribution on flower showed a good match 
between the distribution we observed and their known latitudinal species distribution. Indeed,

242 the narrow and southern range we observed for $C$. lateralis is consistent with Blatrix et al.

243 (2013) that consider this species as absent or very rare above $46^{\circ}$ N. Similarly, the wide

244 latitudinal range of $L$. emarginatus we observed on flowers is consistent with its known

245 presence all over Continental France (Blatrix et al. 2013).

246 Interestingly presence on flowers of $C$. piceus, the last ant species with enough data to analyse 247 its latitudinal distribution, was observed on a much narrower latitudinal range than its known 248 distribution (between 43-50 ${ }^{\circ} \mathrm{N}$, Blatrix et al. 2013). For ants, inter-specific competition is 249 considered as the major driver of community composition (reviewed by Cerdá et al. 2013) and especially competition for food resources (Albrecht and Gotelli 2001, Blüthgen and Fiedler 2004, Lester et al. 2010, Vepsäläinen and Pisarski 1982). Vepsäläinen and Pisarski (1982) 252 divided species in three levels of hierarchy based on their respective dominance in communities: (1) dominants that compete and exclude other species from territory and food resources (2) subdominants that aggressively defend or try to take over food resources and (3) subordinates that defend only their nest. However, most ant assemblage lack of species from the dominant category and some subdominant species clearly act as dominant (Cerdá et al. 257 2013). This pattern has been observed for L. emarginatus in the habitats of Crimea Mountains where its colonies were the largest (around 30000 workers, Stukalyuk and Radchenko 2011) and dominated other species such as $C$. piceus. In our case, dominant and almost strict liquid feeding species such as L. emarginatus (Blatrix et al. 2013) could strongly compete for the food 261 resources produced by the plants (directly such as nectar or indirectly such as aphids honeydew) 262 and outcompete less dominant and more diet generalist species such as $C$. piceus (Blatrix et al. 263 2013). 


\section{Segregate and nested responses to latitude at different taxonomic levels}

Overall, floricolous ants showed a quadratic response to latitude, with maximum occurrence at intermediate latitudes (around $45-46^{\circ} \mathrm{N}$ ). Such pattern echoed the one previously described on the species richness of coprophageous beetles studied along the same latitudinal range (Lobo et and mean annual temperatures which are the most influential spatially structured climate variables along latitudinal gradient of continental France.

273 We highlighted that the presence of the three main subfamilies of floricolous ants exhibited 274 different latitudinal optimums, with Myrmicinae and Dolichoderinae being restricted to lower 275 latitudes whereas Formicinae were more present at medium and high latitudes. Strikingly such a segregated response of ant to latitude was also observed for the lower taxonomical levels we studied, with the presence of the 3 genera of Formicinae showing segregated optimum along

278 the latitudinal gradient (from south to north France: Camponotus, Serviformica and Lasius) and 279 the two species of Camponotus showing the same pattern (from south to north: C. lateralis and C. piceus). Such pattern could result from niche partitioning among ant taxa to minimise competition for resources (reviewed by Schoener 1974), a phenomenon that has been shown to be related to the distribution of ants along large scale environmental gradient (Machac et al. 2011). However, we also observed that the latitudinal segregation was taxonomically aggregated which could be the sign of shared ancestral ecological characteristics. However, more data on various ant species are needed to properly test for a phylogenetic signal in the latitudinal optimum of ants.

\section{Heterogeneous responses to Urbanization and interaction with latitudinal}

\section{gradient}

289 Most ant taxa analysed here showed a negative response to urbanization gradient. This is in accordance with previous studies highlighting a negative impact of urbanization on ant 
abundance (Buczkowski and Richmond 2012) or richness (McKinney 2008, Vepsäläinen et al.

292 2008). Such a negative effect has also been found for other floricolous arthropods, such as

293 Lepidopterans, Coleopterans and Dipterans (Deguines et al. 2012), but also for ground beetles

294 (Vergnes et al. 2014), suggesting that the effect of urbanization on arthropods is general.

295 However, the lower presence of ant visiting flowers in urbanized areas could also be link to a

296 decrease in the "attractivity" of flowers as resources. Urbanization strongly modifies the

297 environment (i.e. soil and air properties, carbon cycle and management) (McDonnell and Hahs

298 2008). These modifications could have altered the properties of nectar (attractiveness, quality

299 or quantity) (Clark et al. 2007, Meindl and Ashman 2013). Moreover, cities are highly

300 heterotrophic systems that produces a lot of resources for invertebrates (McIntyre 2000) such

301 as wastes that are known to be highly attractive for ants (Youngsteadt et al. 2014). Ant might

302 thus neglect floral resources in urban environment, to the profit of other urban specific

303 resources. Finally, exclusive competition by strict liquid eating and dominant ants such as $L$.

304 emarginatus could reinforce such a switch in food resource for omnivorous and less dominant

305 species such as C. piceus or C. lateralis (Blatrix et al. 2013, Cerdá et al. 2013).

306 As expected, we observed a contrasted response to urbanization along the latitudinal gradient

307 with a tendency for a stronger negative effect at lower latitudes. The increase in temperature

308 and decrease of soil moisture along urbanization gradient are considered as general trends

309 (McDonnell and Hahs 2008). However, in regions with a Mediterranean climate such as the

310 lowest latitudinal parts of France, an increase of soil moisture and a decrease of soil temperature

311 along urbanization gradient is frequently observed, mainly due to run-off on impervious

312 surfaces (Holway and Suarez 2006). Those colder and moister conditions are less favorable to

313 most ants, as observed at large scale across Europe (Kumschick et al. 2009). 


\section{Conclusion}

318 Our analysis highlights that both latitude and urbanization affect the distribution of ant-flower

319 interactions and that the coupling of a large dataset collected by citizen scientists with

320 appropriate data validation by experts is an efficient and promising approach. Our results

321 suggested a strong impact of both evolutionary history and competition in shaping the

322 distribution of ant plant interaction across France.

\section{Declarations}

325 We wish to thanks the hundreds of participants of the Spipoll program who collected the data 326 and Mathieu de Flores (OPIE) for coordinating this program.

\section{Conflict of interest disclosure}

329 The authors of this article declare that they have no financial conflict of interest with

330 the content of this article.

333 Additional Supporting Information may be found in the online version of this article:

334 S1 Table. Details of taxonomic levels between studied groups.

\section{References}

337 Albrecht, M. and Gotelli, N. 2001. Spatial and temporal niche partitioning in grassland ants. 338 Oecologia 126: 134-141. 
Antonov, I. 2008. Ant assemblages of two cities with different ecological conditions in southern Cisbaikalia. - Russian J. Ecol. 39: 454-456.

Antonova, V. and Penev, L. 2006. Change in the zoogeographical structure of ants (Hymenoptera: Formicidae) caused by urban pressure in the Sofia region (Bulgaria). Myrmecologische Nachrichten 8: 271-276.

Banque_Mondiale. 2009. Stratégie de la banque mondiale pour les villes et les collectivités territoriales. Note conceptuel et de synthèse. http://www.wburbanstrategy.org/urbanstrategy/sites/wburbanstrategy.org/files/WB\%20Urban \%20Strategy\%20Note\%20\%20--\%20French.pdf.

Baroni Urbani, C. and Collingwood, C. A. 1977. The zoogeography of ants (Hymenoptera, Formicidae) in northern Europe. - Societas pro fauna et flora Fennica.

Bernard, F. 1968. Faune de l'Europe et du Bassin Méditerranéen. 3. Les fourmis (Hymenoptera Formicidae) d'Europe occidentale et septentrionale. - Masson.

Blatrix, R., et al. 2013. Fourmis de France, de Belgique et du Luxembourg. - Delachaux et Niestlé.

Blüthgen, N. and Fiedler, K. 2004. Competition for composition: Lessons from nectar-feeding ant communities. - Ecology 85: 1479-1485.

Buczkowski, G. and Richmond, D. S. 2012. The Effect of Urbanization on Ant Abundance and Diversity: A Temporal Examination of Factors Affecting Biodiversity. - Plos One 7.

Causse, F., et al. 2013. Xper2. Laboratoire d'Informatique en Systématique (LIS), Université Paris VI, France. http://infosyslab.fr/lis/?q=fr/ressources/logiciels/xper2.

Cerdá, X., et al. 2013. Is competition a significant hallmark of ant (Hymenoptera: Formicidae) ecology? - Myrmecological News 18: 131-147.

Clark, P. J., et al. 2007. Effects of urbanization on butterfly species richness, guild structure, and rarity. - Urban Ecosyst 10: 321-337. 
Deguines, N., et al. 2012. The whereabouts of flower visitors: Contrasting land-use preferences revealed by a country-wide survey based on citizen science. - PLoS ONE 7: e45822.

Del Toro, I. 2013. Diversity of Eastern North American Ant Communities along Environmental

Gradients. - PLoS ONE 8: e67973.

Dunn, R. R., et al. 2009. Climatic drivers of hemispheric asymmetry in global patterns of ant species richness. - Ecol. Lett. 12: 324-333.

370 EEA. 2006. Urban sprawl in Europe. - European Environment Agency.

371 EEA. 2010. Corine land cover 2006, version 15. Raster data 25 x 25 meters.

372 http://www.eea.europa.eu/data-and-maps/figures/ds_resolveuid/JJ5CBDYFXB. -.

373 EEA. 2010. The European environment - state and outlook 2010: Synthesis. - European

374 Environment Agency, p. 228.

375 Forys, E. A. and Allen, C. R. 2005. The impacts of sprawl on biodiversity: the ant fauna of the 376 lower Florida Keys. - .

377 Gaston, K. J. 1996. Biodiversity-latitudinal gradients. - Progress in Physical Geography 20: $378 \quad 466-476$.

379 Gaston, K. J. 2000. Global patterns in biodiversity. - Nature 405: 220-227.

380 Herrera, C. M., et al. 1984. Nectar thievery by ants from southern Spanish insect-pollinated 381 flowers. - Insectes Soc. 31: 142-154.

382 Hölldobler, B. and Wilson, E. O. 1990. The ants. - Springer-Verlag.

383 Holway, D. A. and Suarez, A. V. 2006. Homogenization of ant communities in mediterranean 384 California: The effects of urbanization and invasion. - Biol. Conserv. 127: 319-326.

385 Ives, C. D., et al. 2011. The influence of riparian corridor width on ant and plant assemblages 386 in northern Sydney, Australia. - Urban Ecosyst 14: 1-16.

387 Jenkins, C. N., et al. 2011. Global diversity in light of climate change: the case of ants. - Divers. 388 Distrib. 17: 652-662. 
389

390

391

392

393

394

395

396

397

398

399

400

401

402

403

404

405

406

407

408

409

410

411

412

413

414

Johnson, J. B. and Omland, K. S. 2004. Model selection in ecology and evolution. - Trends Ecol. Evol. 19: 101-108.

Jones, C. G., et al. 1994. Organisms as ecosystem engineers. - Oikos 69: 373-386.

Kumschick, S., et al. 2009. Determinants of local ant (Hymenoptera: Formicidae) species richness and activity density across Europe. - Ecol. Entomol. 34: 748-754.

Lessard, J.-P. and Buddle, C. M. 2005. The effects of urbanization on ant assemblages (Hymenoptera: Formicidae) associated with the Molson Nature Reserve, Quebec. - The Canadian Entomologist 137: 215-225.

Lester, P. J., et al. 2010. The role of resource dispersion in promoting the co-occurrence of dominant and subordinate ant species. - Oikos 119: 659-668.

Lobo, J. M., et al. 2002. Modelling the species richness distribution of French dung beetles (Coleoptera, Scarabaeidae) and delimiting the predictive capacity of different groups of explanatory variables. - Global Ecol. Biogeogr. 11: 265-277.

Lomolino, M. V., et al. 2006. Biogeography. - Sinauer Associates.

López-Moreno, I. R., et al. 2003. Social insects in human environments - ants in the city of Coatepec (Veracruz, Mexico). - Sociobiology 42: 605-621.

Machac, A., et al. 2011. Elevational gradients in phylogenetic structure of ant communities reveal the interplay of biotic and abiotic constraints on diversity. - Ecography 34: 364-371.

Majer, J. and Brown, K. 1986. The effects of urbanization on the ant fauna of the Swan Coastal Plain near Perth, Western Australia. - Journal of the Royal Society of Western Australia 69: 1317.

McDonnell, M. and Hahs, A. 2008. The use of gradient analysis studies in advancing our understanding of the ecology of urbanizing landscapes: current status and future directions. Landscape Ecol. 23: 1143-1155.

McIntyre, N. E. 2000. Ecology of Urban Arthropods: A Review and a Call to Action. - Ann. Entomol. Soc. Am. 93: 825-835. 
McKinney, M. 2008. Effects of urbanization on species richness: A review of plants and 416 animals. - Urban Ecosyst 11: 161-176.

417 McKinney, M. L. 2006. Urbanization as a major cause of biotic homogenization. - Biol. 418 Conserv. 127: 247-260.

419 Meindl, G. A. and Ashman, T.-L. 2013. The effects of aluminum and nickel in nectar on the 420 foraging behavior of bumblebees. - Environ. Pollut. 177: 78-81.

421 Moreau, C. S., et al. 2006. Phylogeny of the ants: diversification in the age of angiosperms. 422 Science 312: 101-104.

423 Parmesan, C., et al. 2005. Empirical perspectives on species borders: from traditional 424 biogeography to global change. - Oikos 108: 58-75.

425 Pickett, S. T. A., et al. 2011. Urban ecological systems: Scientific foundations and a decade of 426 progress. - J. Environ. Manage. 92: 331-362.

427 Rico-Gray, V. and Oliveira, P. S. 2007. The Ecology and Evolution of Ant-Plant Interactions.

- University of Chicago Press.

Rolland, J., et al. 2014. Faster speciation and reduced extinction in the tropics contribute to the mammalian latitudinal diversity gradient. - PLoS Biol 12: e1001775.

431 Sala, O., et al. 2000. Global biodiversity scenarios for the year 2100. - Science 287: 1770-1774.

432 Sanford, M. P., et al. 2009. Effects of Urban Development on Ant Communities: Implications 433 for Ecosystem Services and Management

434 Efectos del Desarrollo Urbano sobre Comunidades de Hormigas: Implicaciones para los 435 Servicios y Manejo del Ecosistema. - Conserv. Biol. 23: 131-141.

436 Schoener, T. W. 1974. Resource partitioning in ecological communities. - Science 185: 27-39. 437 Segev, U. 2010. Regional patterns of ant-species richness in an arid region: The importance of 438 climate and biogeography. - J. Arid Environ. 74: 646-652.

439 Stadler, B. and Dixon, A. F. G. 2005. Ecology and evolution of aphid-ant interactions. Annual 440 Review of Ecology Evolution and Systematics. Annual Reviews, pp. 345-372. 
441 Stukalyuk, S. V. and Radchenko, V. G. 2011. Structure of multi-species ant assemblages

442 (Hymenoptera, Formicidae) in the Mountain Crimea. - Entomol. Rev. 91: 15-36.

443 Thompson, B. and McLachlan, S. 2007. The effects of urbanization on ant communities and

444 myrmecochory in Manitoba, Canada. - Urban Ecosyst 10: 43-52.

445 Tylianakis, J. M., et al. 2008. Global change and species interactions in terrestrial ecosystems.

446 - Ecol. Lett. 11: 1351-1363.

447 Uno, S., et al. 2010. Diversity, abundance, and species composition of ants in urban green 448 spaces. - Urban Ecosyst 13: 425-441.

449 Vepsäläinen, K., et al. 2008. The Structure of Ant Assemblages in an Urban Area of Helsinki, 450 Southern Finland. - Ann. Zool. Fenn. 45: 109-127.

451 Vepsäläinen, K. and Pisarski, B. 1982. Assembly of island ant communities. Ann. Zool. Fenn. 452 - JSTOR, pp. 327-335.

453 Vergnes, A., et al. 2014. Urban densification causes the decline of ground-dwelling arthropods.

454 - Biodivers. Conserv. 23: 1859-1877.

455 Willig, M. R., et al. 2003. Latitudinal gradients of biodiversity: pattern, process, scale, and 456 synthesis. - Annual Review of Ecology, Evolution, and Systematics 34: 273-309.

457 Xu, Z., et al. 1998. A study on communities of Formicidae ants in different subtypes of 458 vegetation in Xishuangbanna District of China. - Zoological research/" Dong wu xue yan jiu" 459 bian ji wei yuan hui bian ji 20: 118-125.

460 Youngsteadt, E., et al. 2014. Habitat and species identity, not diversity, predict the extent of 461 refuse consumption by urban arthropods. - Global Change Biol. 21: 1103-1115. 